\title{
Efficacy of Counseling in Reducing Frequency and Severity of Incident Reports in a NARA Unit
}

Initial attempts have been made to delineate the role of psychiatric or mental health services in the federal prison system. These services are provided throughout an inmate's prison term and has not been limited to such sporadic and isolated events as the initial assessment or crisis intervention (Miller, Hendry, Hirsch, Kinzel, Merklin, Shervington, \& Skelton, 1968). During the initial phase of incarceration, inmates must face the issues of separation from the outside world and must adjust to a subordinate role regarding the correctional staff and the acceptance of "forcible restraint" (Miller et al., 1968). The middle phase of incarceration, given its variable duration, requires that the inmate deal with fears of physical assault, homosexual anxiety, and feelings of inadequacy or resentment. The coping behavior, in which the inmate attempts to prevent such stress, may be highly inappropriate or maladaptive (e.g., fabricating or securing a shank, or knife, for defense). Such behavior may result in relocating inmates to a segregation unit (e.g., housing for those who are major disciplinary problems). Emotions that the inmate must deal with include

Ronald C. Riggs is a clinical psychologist, FCI Milan, Michigan. Robert L. Meyer is chief of Psychology Services, FCI Milan, Michigan. Rutham Davis is a doctoral candidate, Guidance and Counseling, University of Michigan, Ann Arbor.

This study was conducted at the Federal Correctional Institution, Milan, Michigan. The authors acknowledge the cooperation of the Bureau of Prisons in this study; however, the material presented here should not be taken as an expression of bureau views and policies. 
include boredom, depression, and anger. The terminal phase may be marked by the "short-time syndrome" (Miller et al., 1968) as well as the fear of returning to a situation that contributed to prior difficulties. As Miller et al. note, "Release also has profound sexual implications for the inmate" (1968, p. 10).

Generally, the mental health profession has taken a modest view of its impact on offenders (Yochelson \& Samenow, 1977). Assessing the effectiveness of such services is an exceptionally complex undertaking. In addition to general considerations and problems (see Wolberg, 1977, pp. 50-67), the current research was conducted on a Narcotic Addict Rehabilitation Act (NARA) unit. Service recipients were typically heroin users with such psychological diagnoses as psychopathic personality or character disorders. Wolbert (1977), when discussing the treatment of addicts, used the phrase "frustratingly unsuccessful" (p. 888) and referred to therapy with character disorders as "difficult" (p. 875) and with psychopathic personalities as "most difficult" (p. 881). All approaches have yielded meager results.

Rather than attempting to assess broad character changes in this study, a more simple outcome measure, the incident report, was selected to assess behavioral change related to counseling involvement. The incident report is a statement of an inmate's inappropriate behavior, which may result in a range of punishments appropriate to the severity of the offense if the inmate is found guilty of the offense.

\section{METHODOLOGY}

\section{Subjects}

A sample of 44 residents of a NARA (Narcotic Addict Rehabilitation Act) unit with guilty charges stated on incident reports was selected. Also chosen were an equal number of residents who had not been found guilty of such charges. The incident report group comprised 19 White residents and 25 Black residents; the no incident report group comprised 13 White residents and 31 Black residents.

\section{Procedure}

The institution's files were used to secure the type and number of incident reports for each resident. The NARA unit files were used to determine each individual's involvement, or lack of involvement, in counseling services. Counseling services were divided into individual, group, and vocational types. Because a specific short-term vocational counseling program, consisting of interest 
assessment, discussion of results, and planning future actions, was operating and was sufficiently different from the more traditional individual counseling. Both were considered separately. A resident involved in more than one type of counseling was counted in each. To determine differences between the three counseling conditions and the noncounseling condition, t-tests of the number of incident reports were performed.

\section{RESULTS}

Of the 88 residents in the study, 43 were involved in some type of counseling; of the 43 involved in counseling, 35 were involved in individual, 13 in group, and 16 in vocational counseling. Of the same 43 persons involved in counseling, 26 had no incident reports and 17 had at least one such report. Of the 45 persons not involved in counseling, 18 had no incident reports and 27 had at least one such report (see Table 1).

In comparing counseling involvement with noncounseling involvement, the 43 residents in counseling received 36 incident reports $(\bar{X}=.84)$; the 45 residents not in counseling received 59 incident reports $(\bar{X}=1.31)$. This approaches statistical significance $(\mathrm{p}<.07)$.

Comparing individual counseling and noncounseling involvement, the 35 residents in individual counseling received 36 incident reports $(\bar{X}=1.03)$; the noncounseling group received 59 incident reports $(\bar{X}=1.31)$. This difference is not statistically significant $(\underline{p}<.21)$.

Comparing group.counseling and noncounseling involvement, the 13 residents in group counseling received 5 incident reports $(\bar{X}=.38)$; the noncounseling group received 36 incident reports $(\bar{X}=1.31)$. This difference is statistically significant $(p<.025)$.

Comparing vocational counseling and noncounseling involvement, the 16 residents in vocational counseling received 4 incident

TABLE 1

Distribution of Sample $(\underline{N}=88)$

According to Counseling Involvement and Incident Reports

\begin{tabular}{lccc}
\hline & \multicolumn{2}{c}{ INCIDENT REPORTS } & \\
\cline { 2 - 4 } Counseling Involvement & YES & NO & Total \\
\hline Yes & 17 & 26 & 43 \\
No & 27 & 18 & 45 \\
Total & 44 & 44 & \\
\hline
\end{tabular}


Comparison of Types of Counseling Involvement With No Such Involvement on Frequency of Incident Reports

\begin{tabular}{lcccc}
\hline $\begin{array}{c}\text { Type of } \\
\text { Counseling }\end{array}$ & $\begin{array}{c}\text { Incident } \\
\text { Reports }\end{array}$ & $\underline{\mathrm{n}}$ & $\begin{array}{l}\text { Incident } \\
\text { Reports/n }\end{array}$ & Probability \\
\hline None & 59 & 45 & 1.31 & \\
Any & 36 & 43 & .84 & .07 \\
Individual & 36 & 35 & 1.03 & .21 \\
Group & 5 & 13 & .38 & .025 \\
Vocational & 4 & 16 & .25 & .005 \\
\hline
\end{tabular}

reports $(\bar{X}=.25)$; the noncounseling group received 36 incident reports $(\bar{X}=1.31)$. This difference is statistically significant $(\underline{p}<.005)$. (All the results cited are summarized in Table 2.) The types of violations noted in the incident reports for the 17 residents involved in counseling and the 27 residents not so involved were categorized using the Bureau of Prison's coding scheme (summarized in Table 3.) Because of the large number of: categories and the relatively small sample size, meaningful statistical analyses were not possible; however, a visual inspection of these data reveals two trends: (a) 12 incidents for the noncounseling group as opposed to 1 incident for the counseling group - assault (002), fighting (003), threatening bodily harm (004), and fighting in self-defense (013); and (b) 16 incidents for the noncounseling group as opposed to 0 incidents for the counseling group unauthorized use of the mail (701), unauthorized contacts with the public (702), and money given to another inmate, family, or friends (752).

\section{DISCUSSION}

Two findings of this study seem significant. The first finding is that the NARA residents studied who were involved in counseling have a fewer number of incident reports than do their counterparts who were not involved. Generalizations of the most effective type of counseling cannot be made at this time because of the low number of persons involved in group or vocational counseling. A combination of different types of counselong may hold promise, however. It should be noted here that no process measures were used to assess counselor effectiveness. In accordance with previous studies that of course may be the relevant variable. 


\section{TABLE 3}

Frequency of Types of Incident Report for Counseling $(\underline{n}=17)$ And No Counseling ( $\underline{n}=27)$ Groups

\begin{tabular}{|c|c|c|c|c|c|}
\hline \multicolumn{2}{|c|}{ Incident Report Code } & \multicolumn{2}{|c|}{$\begin{array}{l}\text { Counseling } \\
\text { Group }\end{array}$} & \multicolumn{2}{|c|}{$\begin{array}{c}\text { No Counseling } \\
\text { Group }\end{array}$} \\
\hline & & $F$ & $\%$ & $\underline{F}$ & $\%$ \\
\hline 002 & Assault & 0 & 0.0 & 2 & 2.1 \\
\hline 003 & Fighting & 1 & 1.8 & 2 & 2.1 \\
\hline 004 & Threatening bodily harm & 0 & 0.0 & 6 & 6.3 \\
\hline 013 & Fighting in self-defense & 0 & 0.0 & 2 & 2.1 \\
\hline 051 & Engaging in sexual act with others & 3 & 5.3 & 1 & 1.1 \\
\hline 103 & Wearing a disguise or mask & 1 & 1.8 & 0 & 0.0 \\
\hline 152 & Destroying government property & 0 & 0.0 & 1 & 1.1 \\
\hline 153 & Stealing (theft) & 1 & 1.8 & 0 & 0.0 \\
\hline 201 & Possession of an explosive & 1 & 1.8 & 0 & 0.0 \\
\hline 202 & Possession of a weapon & 0 & 0.0 & 1 & 1.1 \\
\hline \multirow[t]{2}{*}{203} & Possession of narcotics, drugs or & & & & \\
\hline & intoxicants & 4 & 7.0 & 7 & 7.4 \\
\hline 206 & Possession of property of another & 0 & 0.0 & 1 & 1.1 \\
\hline 208 & Possession of unauthorized item & 3 & 5.3 & 5 & 5.3 \\
\hline 254 & Refusal to work & 2 & 3.5 & 5 & 5.3 \\
\hline 255 & Encouraging others to refuse to work & 0 & 0.0 & 1 & 1.1 \\
\hline 256 & Refusing to obey an order & 10 & 17.5 & 14 & 14.7 \\
\hline 301 & Unexcused absence from assignment & 12 & 21.1 & 8 & 8.4 \\
\hline 303 & Failing to perform work as instructed & 0 & 0.0 & 2 & 2.1 \\
\hline 304 & Insolence towards a staff member & 2 & 3.5 & 5 & 5.3 \\
\hline 305 & Lying or providing a false statement & 4 & 7.0 & 1 & 1.1 \\
\hline 306 & Conduct which disrupts & 4 & 7.0 & 6 & 6.3 \\
\hline 402 & Being in an unauthorized area & 7 & 12.3 & 8 & 8.4 \\
\hline 552 & Being intoxicated & 0 & 0.0 & 1 & 1.1 \\
\hline 554 & Using abusive or obscene language & 1 & 1.8 & 0 & 0.0 \\
\hline 701 & Unauthorized use of mail & 0 & 0.0 & 6 & 6.3 \\
\hline & Unauthorized contact with the public & 0 & 0.0 & 5 & 5.3 \\
\hline & Giving money to another inmate, family, & & & & \\
\hline & friends & 0 & 0.0 & 5 & 5.3 \\
\hline \multirow[t]{3}{*}{801} & Attempting to commit or aiding to any of & & & & \\
\hline & the above & 1 & 1.8 & 0 & 0.0 \\
\hline & Total & 57 & 100 & 95 & 100 \\
\hline
\end{tabular}


It cannot be said with certainty that counseling is the causal factor in lowering the rate of incident reports; an experimental study using a more sophisticated design might be conducted because the results obtained here are encouraging. Another significant finding is that the rate of more serious or violent types of incident reports seems notably lower for residents who are involved in counseling.

These results indicate that mental health services may be effective in the behavioral management of addicts, psychopathic personalities, and character disorders. Wolberg (1977) agrees that treatment goals should be geared toward behavioral rather than characterological or personality change.

Although no systematic analysis of inmates' feelings toward programming was attempted, it was noted that the inmates studied were in all three stages: initial, middle, and terminal (Miller et al., 1977). This supports the contention that mental health services that extend throughout the term of incarceration have applicability and beneficial effects.

\section{REFERENCES}

Miller, W. B.; Hendry, C. H.; Hirsch, S. J.; Kinzel, A. F.; Merklin, L., Jr.; Shervington, W. W.; \& Skelton, W. D. A handbook of correctional psychiatry. Washington, D.C.: U. S. Bureau of Prisons, Department of Justice, 1968.

Wolberg, L. R. The technique of psychotherapy,(3rd ed.). New York: Grune \& Stratton, 1977.

Yochelson, S., \& Samenow, S.E. The criminal personality. New. York: Jason Aronson, 1977. 